\title{
Decreasing Trend in Global Land Monsoon Precipitation over the Past 50 Years Simulated by a Coupled Climate Model
}

\author{
LI Hongmei ${ }^{1,2}$ (李红梅), ZHOU Tianjun*1 (周天军), and LI Chao ${ }^{3}$ (李 超) \\ ${ }^{1}$ State Key Laboratory of Numerical Modeling for Atmospheric Sciences and Geophysical Fluid Dynamics, \\ Institute of Atmospheric Physics, Chinese Academy of Sciences, Beijing 100029 \\ ${ }^{2}$ Graduate University of the Chinese Academy of Sciences, Beijing 100049 \\ ${ }^{3}$ International Max Planck Research School on Earth System Modeling, \\ and Max Planck Institute for Meteorology, Hamburg, Germany 20146
}

(Received 4 November 2008; revised 30 April 2009)

\begin{abstract}
The authors examine the effects of external forcing agents such as greenhouse gases (GHGs) and aerosols, as well as solar variability and ozone, on global land monsoon precipitation by using a coupled climate model HadGEM1, which was developed by the Met Office Hadley Centre for Climate Research. The results indicate that HadGEM1 performs well in simulating the observed decreasing trend of global land monsoon precipitation over the past 50 years. This trend mainly occurred in the Northern Hemisphere and is significantly different from the trend of natural variability due to ocean-atmosphere-land interactions. The coherence between the simulation and the observations indicates that the specified external forcing agents, including GHGs and aerosols as well as solar variability and ozone, are important factors that have affected the decreasing trend of global land monsoon precipitation in the past 50 years.
\end{abstract}

Key words: monsoon precipitation, decreasing trend, coupled climate model, external forcings

Citation: Li, H. M., T. J. Zhou, and C. Li, 2010: Decreasing trend in global land monsoon precipitation over the past 50 years simulated by a coupled climate model. Adv. Atmos. Sci., 27(2), 285-292, doi: $10.1007 / \mathrm{s} 00376-009-8173-9$.

\section{Introduction}

The monsoon is an important aspect of the global climate system. About two-thirds of humanity inhabits the monsoon region; the economy and society across the region are greatly influenced by the evolution and variability of the monsoon (Huang et al., 2003). Monsoon precipitation plays an important role in determining the global atmospheric general circulation and hydrological cycle. Investigating the variation of global monsoon precipitation over the past 50 years, especially how the monsoon precipitation responds to external forcing agents, such as greenhouse gases (GHGs) and aerosols as well as solar variability and ozone, may help us understand future climate change.

The global monsoon system includes the AsianAustralian, African, and American monsoon. Many published studies have focused on long-term trends of specific monsoon systems such as the East Asian summer monsoon (Yu et al., 2004; Yu and Zhou, 2007; Li et al., 2008; Zhou et al., 2009a, b, c). Previous studies have shown that the monsoonal overturning circulations have diminished over the Australian and African regions (Chase et al., 2003), the precipitation amount has decreased in the rainy season over North and South Africa (Hoerling et al., 2006), and the Asian summer monsoon has weakened (Ding and Sun, 2004; Zhao and Zhou, 2005) over the past 50 years. The global air-sea system experienced a shift in the late 1970s, which resulted in significant warming in most parts of the world (Trenberth and Hurrell, 1994; Yang et al., 2002). Modeling studies have revealed that anthropogenic forcing, mainly by GHGs, can reproduce the observed global warming trend in the second half of the

\footnotetext{
${ }^{*}$ Corresponding author: ZHOU Tianjun, zhoutj@lasg.iap.ac.cn
} 
20th century (Stott et al., 2006; Hegerl et al., 2007). Many studies have discussed the relationship between global warming and monsoon variations (Hulme, 1996; Gong et al., 2000; Chase et al., 2003; Kripalani et al., 2003). Some scientists have focused on the influences of aerosols on monsoon variations (Menon et al., 2002; Qian et al., 2003; Lau et al., 2006). However, the influence of external forcings on long-term monsoon variability remains an open question.

Earlier investigations discussing variations of the monsoon and its causes mostly focus on sub-monsoon systems. Analysis of the global average of land precipitation series over the past 100 years indicates that precipitation variations in different regions are related to each other (Gong and Wang, 1999). This suggests that a global perspective is more useful to evaluate changes of monsoon climate. Recently, Wang and Ding (2006) proposed a global monsoon index, which provides a good criterion for studying the global monsoon precipitation in total. Their results suggest an overall weakening of the global land monsoon precipitation over the past half-century, primarily due to the weakening of the summer monsoon rainfall in the Northern Hemisphere. This decreasing tendency is evident in many regional monsoon indices (Zhou et al., 2008a). Further study shows that this significant change in global land monsoon precipitation is deducible from the atmosphere's response to the observed SST variations, especially tropical ocean warming (Zhou et al., 2008b). Kim et al. (2008) evaluated simulations from 21 coupled global climate models (CGCMs) which participated in the World Climate Research Programme's Coupled Model Intercomparison Project phase 3 (CMIP3), and found that the multimodel ensemble simulated a reasonably realistic climatology of the global monsoon precipitation and circulation and a weak trend in the Northern Hemisphere land monsoon index.

Is the decreasing trend in global land monsoon precipitation over the past 50 years due to internal variability of the coupled ocean-atmosphere-land system, or the response to external forcings? To answer this question, we use the output of a state-of-theart coupled climate model, specifically the Met Office Hadley Centre Global Environment Model Version1 (HadGEM1), which is a useful tool for understanding the impacts of external forcings on monsoon precipitation. The purpose of this study is to evaluate the ability of the coupled climate model to simulate monsoon precipitation, and to address the possible connection between the decline in global land monsoon precipitation and external forcings (GHGs, aerosols, solar irradiation, ozone).

The rest of the paper is organized as follows. In section 2, we describe the model, data, and methods. The primary results are presented in section 3 , and a summary associated with a brief discussion is given in section 4 .

\section{Model, data, and methodology}

HadGEM1 has a nonhydrostatic atmospheric dynamical core, and semi-Lagrangian advection and semi-implicit timestepping are employed in the atmospheric component of the model, specifically HadGAM1. The horizontal resolution is $1.25^{\circ}$ (lat) $\times$ $1.875^{\circ}$ (lon) with 38 layers in the vertical, extending to over $39 \mathrm{~km}$ in height (Webb et al., 2001; Johns et al., 2004; Roberts, 2004; Davies et al., 2005). The ocean submodel HadGOM1 is based on the BryanCox code (Roberts, 2004). Its resolution is $1^{\circ} \times 1^{\circ}$ outside the tropics, increasing to $(1 / 3)^{\circ}($ lat $) \times 1^{\circ}$ (lon) at the equator. There are 38 layers in the vertical, and the resolution increases from the bottom to the surface, where it is $10 \mathrm{~m}$. The sea ice component of HadGEM1 is more complex than that of its predecessor, HadCM3; elastic-viscous-plastic ice dynamics are employed and Los Alamos National Laboratory sea ice model's ice ridging scheme is used (Hunke and Dukowicz, 1997; Lipscomb, 2001; Hunke and Lipscomb, 2004). HadGAM1 is physically coupled with HadGOM1 through the exchange of fluxes of wind stress, incoming radiation, moisture, and sea ice properties; as the land-sea masks for HadGAM1 and HadGOM1 differ because of their different horizontal resolutions, a coastal tiling method is adopted to achieve a conservative flux coupling (Oki and Sud, 1998; Johns et al., 2006). For more details on the HadGEM1 model, see Johns et al. (2006).

The output of the HadGEM1 simulations used in this study are from the "climate of the 20th century experiment" (referred to as 20C3M) and the "preindustrial control experiment" (referred to as PICNTRL) of CMIP3. The 20C3M experiment runs from 1860 to 2000 , covering the pre-industrial period and the global warming in the late 20th century. Since historical atmospheric forcings (i.e., GHGs, aerosols, ozone, and solar radiation) were used to force the coupled model, the simulated results correspond to the actual calendar to some extent; however, this correspondence is mainly evident at the decadal scale and in long-term trends (Zhou and Yu, 2006). In the PICNTRL run, the GHGs and other external forcings were fixed to the pre-industrial levels, so variations of monsoonal precipitation arise from the natural variability induced by the ocean-atmosphere-land interaction. A 140-year integration was performed in the PICNTRL run. The 20C3M run includes two realizations, and 
the ensemble mean of these two realizations is analyzed. We focus on the period of 1948-1999 in this study.

Three sets of monthly rain gauge precipitation data, i.e., Delaware, Climate Research Unit (CRU), and Precipitation REConstruction over Land (PREC/L), are used here as observational sources (Hulme et al., 1998; Willmott and Matsuura, 2001; Chen et al., 2002). To facilitate analysis and reduce the uncertainties from different data sources, the original data were interpolated onto a $1^{\circ} \times 1^{\circ}$ grid and the ensemble mean was calculated for the period of 19481999. Since only land precipitation data is available in these three data sets, the CPC Merged Analysis of Precipitation (CMAP) data for the period of 1979-1999 is also used in our analysis (Xie and Arkin, 1996).

Following Wang and Ding (2006), we used the annual range (AR) as the local summer-minus-winter precipitation in this analysis. The global monsoon domain is defined by the region where the AR exceeds $180 \mathrm{~mm}$ and the local summer monsoon precipitation exceeds $35 \%$ of the annual rainfall. The results from this simple definition are in agreement with that from more complex criteria (Wang and LinHo, 2002). We also calculated the regionally averaged summer monsoon precipitation in the Northern Hemisphere (NH), the Southern Hemisphere ( $\mathrm{SH})$, and the whole globe, and denoted these results as the NH monsoon in- dex (NHMI), the SH monsoon index (SHMI), and the global monsoon index (GMI), respectively. To verify whether the model can reproduce the weakening trend of monsoon precipitation under historical atmospheric forcings, we employed empirical orthogonal function (EOF) decomposition to analyze the AR change. The leading temporal mode was termed the annual range index (ARI). Mann-Kendall rank statistics (Kendall, 1955) were used to test the significance of linear trends.

\section{Results}

\subsection{Climatology of global monsoon precipita- tion}

Before discussing the changes of monsoon precipitation, we evaluated the climatological monsoon precipitation simulated by HadGEM1. Figure 1 shows the climatological mean AR. The bold lines delineate the global monsoon domain. The observations are based on CMAP precipitation data (Fig. 1a). The observations show that the major monsoon rainy regions tend to reside on each side of the perennial equatorial rainfall regions, i.e., Africa, Asia, Australia, and America. The HadGEM1 model has a reasonable performance in simulating the main monsoon precipitation (Fig. 1b), although the simulated AR is slightly larger than the observation. The model produces less monsoon precipitation over the tropical South Pacific, India,

(a) Observation

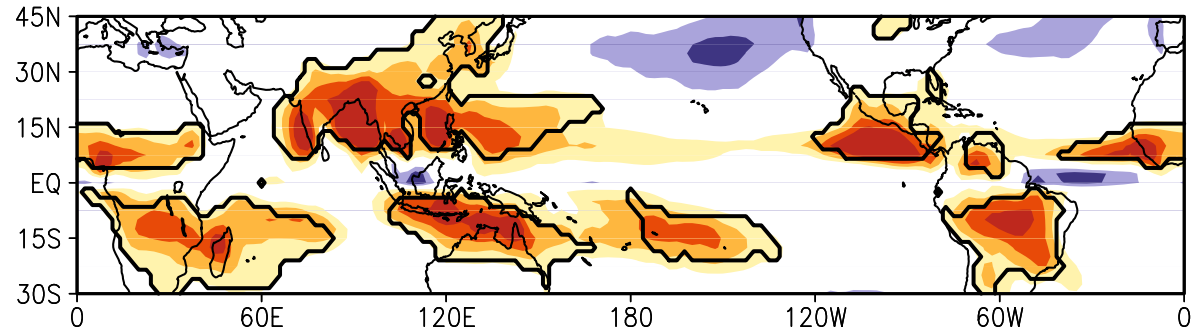

(b) UKMO-HadGEM 1

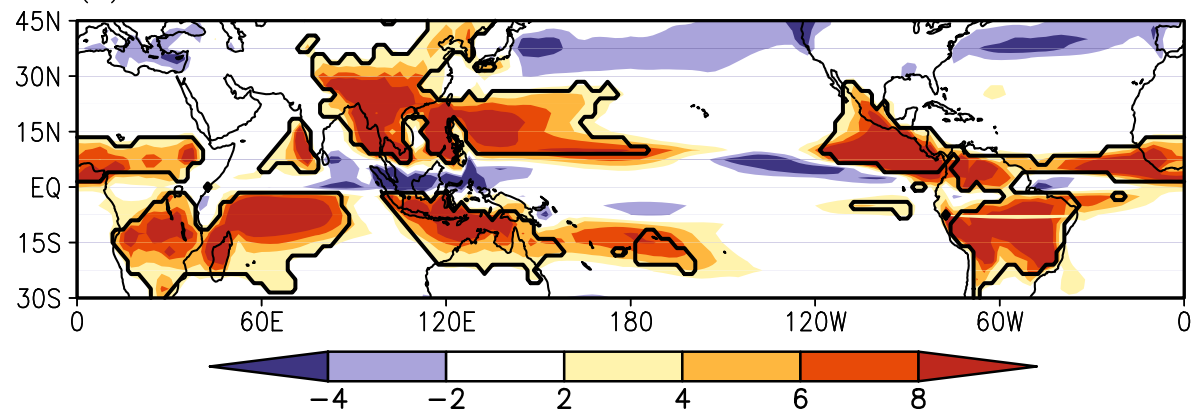

Fig. 1. The climatological mean for the annual range (AR) of precipitation defined by the local summer mean precipitation rate minus the local winter mean precipitation rate. The bold lines delineate the global monsoon domain. (a) CMAP observations, (b) the HadGEM1 simulation (units: $\mathrm{mm} \mathrm{d}^{-1}$ ). 
and the mid-low Yangtze River valley over China, but the simulated monsoon region is larger than the observation over the western Pacific and the southern Indian Ocean. The monsoon regions over the southern part of North America, the northern part of South America, and in northern Africa are detached in the observations, but combined in the simulation.

\subsection{Trend in global land monsoon precipita- tion}

The simulated spatial pattern of the leading EOF mode of the normalized AR over the global continental monsoon regions is shown in Fig. 2a. The fractional variance of the leading EOF mode is $12.3 \%$, which is comparable to that of Wang and Ding (2006). The majority of land monsoon regions in observations show a coherent decreasing trend (Wang and Ding, 2006). The simulation is more consistent with the observations in the $\mathrm{NH}$ than in the $\mathrm{SH}$, and this feature is also consistent with a recent simulation of an Atmosphere General Circulation Model forced by historical sea surface temperature (Zhou et al., 2008b). One possible reason may be that the observations in the $\mathrm{SH}$ are much fewer than those in the $\mathrm{NH}$, and many parameter schemes in current models are based on observations in the $\mathrm{NH}$, and hence may not have as good performance in the $\mathrm{SH}$ as in the NH. There are negative anomalies over southern Africa and northern Australia. The spatial pattern of the leading EOF mode over the South American monsoon region shows a zonal dipole pattern. Negative anomalies are evident in South Asia. The observed positive polarities over India and East China are absent in the simulation. Although the trend of normalized ARI is weaker than the observations $\left[-2.12(50 \mathrm{yr})^{-1}\right]$, it should be noted that the corresponding principle component or ARI shows a significant decreasing tendency $\left[-1.95(50 \mathrm{yr})^{-1}\right]$ for the entire period examined (Fig. 2b).

We also projected the PICNTRL simulated AR onto the first EOF mode simulated by 20C3M, and obtained the PICNTRL simulated ARI. The normalized time series also shows a decreasing trend $[-0.80(50$ $\mathrm{yr})^{-1}$, but this is not statistically significant, which indicates that the external forcings play a key role in the global land monsoon rainfall decrease in the past 50 years. Concerning the interannual scale variability, we cannot find any correspondence between the observations and the simulation in the ARI series; the correlation coefficient between the detrended observed ARI and 20C3M simulated ARI is only 0.03. This is consistent with the result of Zhou and $\mathrm{Yu}$ (2006), who found that when driven by historical forcing agents including GHGs, aerosols, solar irradiation, etc., current state-of-the-art coupled climate models have reasonable performance in simulating trends and interdecadal variations, but barely any skill in reproducing interannual variations.

To validate the effects of external forcings on the

(a)First EOF of annual range (12.3\%)

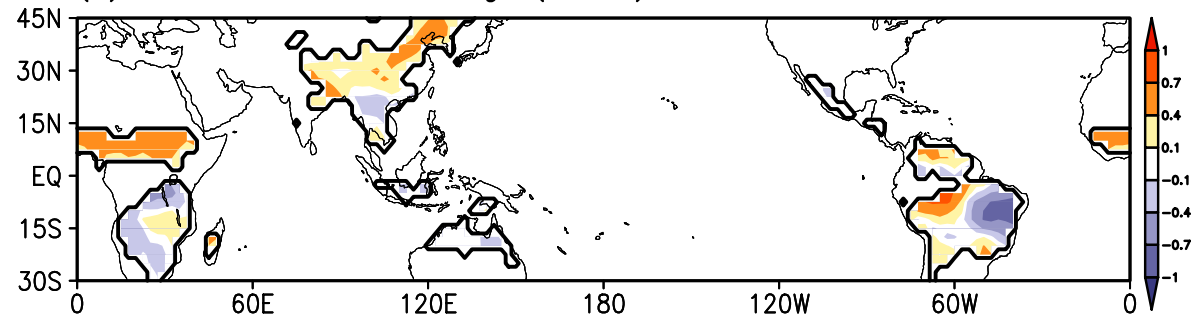

(b)Leading principle component

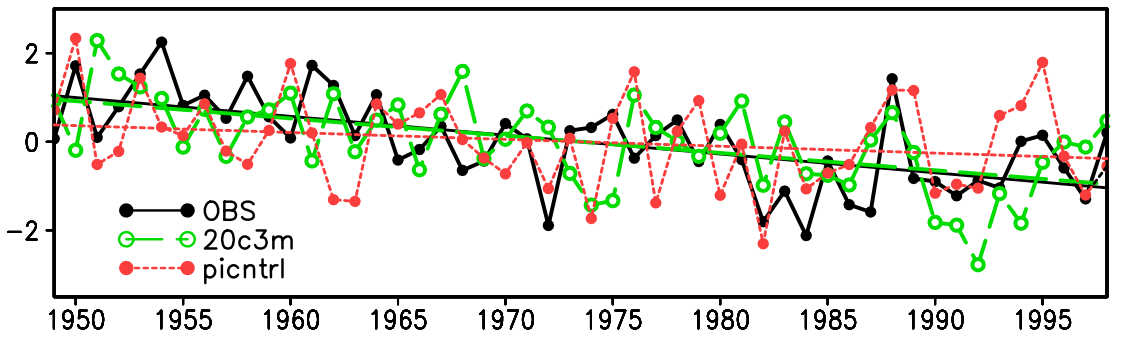

Fig. 2. (a) The spatial pattern of the leading Empirical Orthogonal Function (EOF) mode of the normalized AR anomalies over the global continental monsoon regions in the HadGEM1 simulation (unitless). (b) The corresponding principle component or ARI of 20C3M and PICNTRL are shown as green dashed line with open circles, and red dotted line with filled circles, respectively. The observed time series shown with a black solid line and filled circles in (b) is from Wang and Ding (2006). 
global land monsoon precipitation decrease, we employ probability density functions (PDFs) to normalized ARI trends simulated by PICNTRL (Fig. 3). The ARI was obtained by projecting the PICNTRL simulated AR onto the EOF1 pattern simulated by 20C3M. The external forcings were fixed to their levels in the pre-industrial period in the PICNTRL experiment, and hence the simulation reflects internal variation of the coupled system. We randomly chose 50 years from the 140-year time series, calculated their trends, and counted the frequency with which the results fell in each trend bin. Finally, we got a PDF distribution, which could represent the trend distribution coming from internal variations of the coupled oceanatmosphere-land system. The PDF shows a quasinormal distribution, with trend values between -1.2 $(50 \mathrm{yr})^{-1}$ and $1.2(50 \mathrm{yr})^{-1}$. The trend of the observations is $-2.12(50 \mathrm{yr})^{-1}$, while the trend of the 20C3M simulation is $-1.95(50 \mathrm{yr})^{-1}$; both values are far outside of the PDF of the PICNTRL run. This supports the possibility that the land monsoon rainfall trend in the forced run should not be attributed to natural variability. Compared to the PICNTRL run, the closer resemblance of the $20 \mathrm{C} 3 \mathrm{M}$ run to the observations suggests that the external forcings, including GHGs and aerosols, solar variability, and ozone, are important factors for the weakening tendency of global land monsoon precipitation. The internal variability due to ocean-atmosphere-land interaction should not be seen as the mechanism responsible for the decreasing tendency of global land monsoon precipitation.

\subsection{Different responses in the Northern Hemisphere and Southern Hemisphere}

The time series of NHMI, SHMI, and GMI are

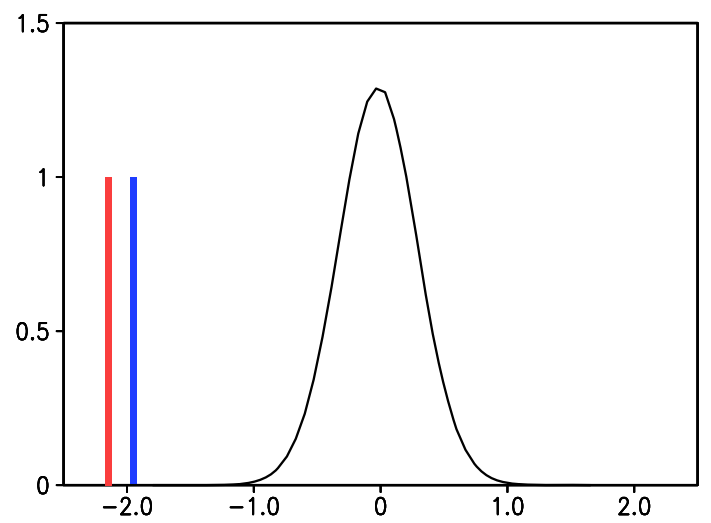

Fig. 3. PDFs of normalized ARI trends from the 140year pre-industrial control run. The trends from observations and $20 \mathrm{C} 3 \mathrm{M}$ simulation are shown by the red and blue bars, respectively. The $x$-axis represents the trend value, while the $y$-axis represents the corresponding frequency. shown in Fig. 4. The time series are given as anomalies relative to the climate mean. The simulated climate mean values of the NHMI, SHMI, and GMI are larger than observed; the corresponding values of the observations (simulation) are $6.51 \mathrm{~mm}(7.48 \mathrm{~mm}), 6.48 \mathrm{~mm}$ $(8.46 \mathrm{~mm})$, and $6.50 \mathrm{~mm}(7.97 \mathrm{~mm})$, respectively. The observed NHMI shows a significant decreasing trend, which is also apparent in GMI, but is not significant in SHMI. The observed decreasing trend in the NHMI can be found in the HadGEM1 simulation. It is, however, slightly larger than observed, with a trend of $\left[-0.68 \mathrm{~mm} \mathrm{~d}^{-1}(50 \mathrm{yr})^{-1}\right]$ versus the observed value of $\left[-0.52 \mathrm{~mm} \mathrm{~d}^{-1}(50 \mathrm{yr})^{-1}\right]$. The simulated GMI decreasing trend $\left[-0.33 \mathrm{~mm} \mathrm{~d}^{-1}(50 \mathrm{yr})^{-1}\right]$ is comparable to the observed trend $\left[-0.32 \mathrm{~mm} \mathrm{~d}^{-1}(50 \mathrm{yr})^{-1}\right]$. The simulated SHMI shows no apparent trend $[0.01$ $\mathrm{mm} \mathrm{d}^{-1}(50 \mathrm{yr})^{-1}$, which is consistent with the observations $\left[-0.11 \mathrm{~mm} \mathrm{~d}^{-1}(50 \mathrm{yr})^{-1}\right]$.

In addition to the decreasing trend, the three monsoon indices also show robust interannual variability. The correlation coefficients of NHMI, SHMI, and GMI between the simulation and observations are $0.37,0.10$,

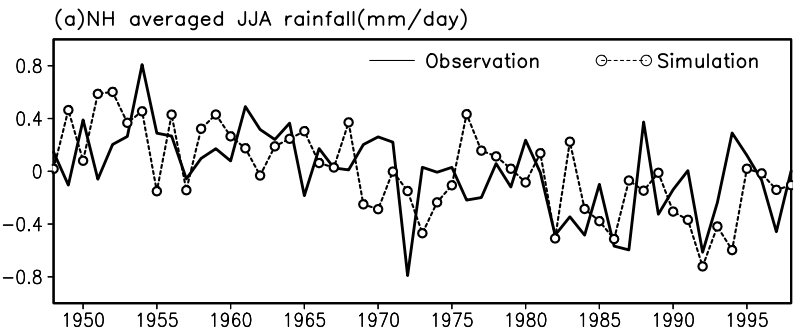

(b) $\mathrm{SH}$ averaged DJF rainfall( $\mathrm{mm} /$ day)

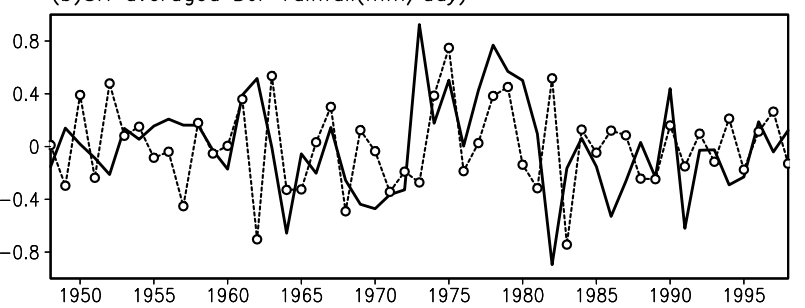

(c) $\mathrm{NH}+\mathrm{SH}$ averaged local summer rainfall( $\mathrm{mm} /$ day $)$

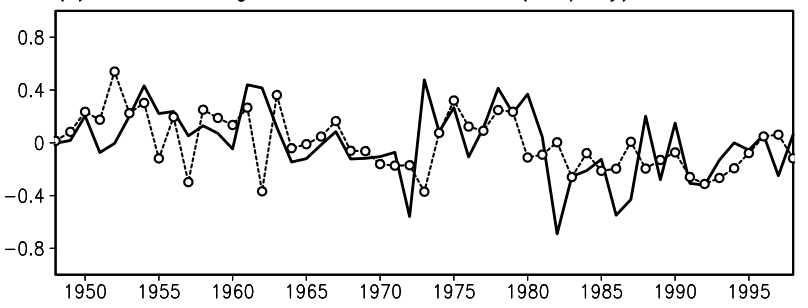

Fig. 4. Time series of (a) the Northern Hemisphere monsoon index (NHMI), (b) the Southern Hemisphere monsoon index (SHMI), and (c) the global monsoon index (GMI), or the sum of (a) and (b). The time series are given as anomalies relative to the climate mean. 
and 0.31 , respectively. The correlation between simulation and observations for NHMI and GMI are statistically significantly at the $5 \%$ level. After linear detrending, the correlation coefficients are 0.08, 0.11, and 0.17 , respectively, which are no longer statistically significant at the $5 \%$ level. The discrepancy between the original and detrended time series indicates that the significant correlation between the simulation and the observations mainly comes from the long-term trend in NHMI.

By using the GPCP data set, Wang and Ding (2006) found that there was an increasing trend over the oceanic summer monsoon region since 1979, but this result is still in need of validation because of the uncertainty of satellite data over the ocean monsoon region (Zhou et al., 2008b). The simulated ocean monsoon precipitation shows a decreasing trend, with a trend of $-0.41 \mathrm{~mm} \mathrm{~d}^{-1}(50 \mathrm{yr})^{-1}\left[-0.50 \mathrm{~mm} \mathrm{~d}^{-1}(50\right.$ $\mathrm{yr})^{-1}$ ] over the last 50 years (last 20 years).

\section{Summary and discussion}

\subsection{Summary}

As revealed by Wang and Ding (2006) and Zhou et al. (2008a), the global land monsoon precipitation has decreased over the last 50 years of the 20th century. To explore the reason(s) responsible for this decreasing tendency, this paper examines the impacts of external forcing agents including GHGs and aerosols, as well as solar variability and ozone, on monsoon variations by using the output of HadGEM1, which was run by the Met. Office Hadley Centre. The main results are summarized below.

(1) HadGEM1 has a reasonable performance in simulating the observed global monsoon precipitation regions, except the simulated AR is larger than observed.

(2) The 20C3M simulation results show that HadGEM1 performs well in simulating the downward trend of global land monsoon precipitation over the past half century when driven by historical GHG forcing and aerosols, as well as solar variability and ozone. The simulated decreasing trend $\left[-2.12(50 \mathrm{yr})^{-1}\right]$ of normalized ARI is consistent with the observations $\left[-1.95(50 \mathrm{yr})^{-1}\right]$, although there exists a slight difference in intensity. The ARI trends from the observations and the 20C3M simulation are far outside of the PDF of the PICNTRL run. This reveals that the land monsoon rainfall trend in the forced run should not be attributed to natural internal variability. The coherent decreasing tendencies in the 20C3M simulation and the observations indicate that external forcings play an important role in the global land monsoon precipitation decrease over the past 50 years.
(3) As in the observations, the NHMI of the HadGEM1 20C3M run shows a significant decreasing trend, and this decreasing trend is also apparent in GMI, but is not significant in SHMI. The high correlation between observed and simulated monsoon indices mainly comes from long-term trend of NHMI.

\subsection{Discussion}

Studying how the monsoon precipitation responds to external forcing agents such as GHGs and aerosols, as well as solar irradiation and ozone, may help us understand future climate variations. Our results show that the external forcings are important factors that may have affected the global monsoon precipitation, which shows a decrease over the past 50 years. However, it is important to acknowledge the limitations of this study. The observed decreasing tendencies of monsoonal precipitation over India and East China are absent in the simulation of HadGEM1. Discussions about the mechanisms responsible for the precipitation variations over India and East China have been limited by the poor performance of climate models (Zhou et al., 2009d; Li et al., 2008).

Another potential limitation is the SST change in response to external forcings. Zhou et al. (2008b) has shown that when forced by historical sea surface temperatures covering the 1950-2000 period, the ensemble simulation with the NCAR Community Atmosphere Model version 2 (CAM2), successfully reproduced the weakening tendency of global land monsoon precipitation. This decreasing tendency was mainly caused by the warming trend over the central-eastern Pacific and the western tropical Indian Ocean. Their work suggests that the significant change of the global land monsoon precipitation may be deducible from the atmosphere's response to the observed SST variations. Further study to identify and understand the cause of these SST anomalies will also have implications for projections of global land monsoon precipitation changes, particularly the response to external forcing agents such as GHGs and aerosols, as well as solar irradiation and ozone. This kind of work can help build up a framework to understand the variation of global land monsoon precipitation and its future changes.

Finally, Kim et al. (2008) evaluated the CMIP3 multimodal dataset. They found that 5-7 out of 21 models could partly reproduce the observed NHMI decreasing trend at an acceptable confidence level. Why are most models not able to capture the global land monsoon precipitation change? Is it due to unrealistic SST variability, or parameterization scheme problems in the models? All these questions warrant further studies. 
Acknowledgements. This work was supported by National Natural Science Foundation of China under Grant Nos. 40625014, 40821092, and 90711004, the National Basic Research Program of China (2006CB403603), and the China Meteorological Administration (GYHY200706010, GYHY200706005). We acknowledge the World Climate Research Programme (WCRP) for their efforts in coordinating coupled climate models experiments. We acknowledge the Hadley Center for providing the model output. We thank Ms. Judith Aplon for her help in editing the English.

\section{REFERENCES}

Chase, T., J. Knaff, R. Pielke, and E. Kalnay, 2003: Changes in Global Monsoon Circulations Since 1950. Natural Hazards, 29, 229-254.

Chen, M., P. Xie, J. E. Janowiak, and P. A. Arkin, 2002: Global land precipitation: A 50-yr monthly analysis based on gaugeobservations. Journal of Hydrometeorology, 3, 249-266.

Ding, Y., and Y. Sun, 2004: Changes in Asian summer monsoon and possible mechanisms. Newsletter on Climate Change 2003/2004, 47-49.

Davies, T., M. Cullen, A. Malcolm, M. Mawson, A. Staniforth, A. White, and N. Wood, 2005: A new dynamical core for the Met Office's global and regional modelling of the atmosphere. Quart. J. Roy. Meteor. Soc., 131, 1759-1782.

Gong, D., and S. Wang, 1999: The influences of ENSO on precipitation over global land and China in recent 100 years. Chinese Science Bulletin, 44, 315-320. (in Chinese)

Gong, D., S. Wang, and J. Zhu, 2000: Surplus summer rainfall along the middle to lower reaches of Changjiang River in the 1990s. Acta Geographica Sinica, 55, 567-575. (in Chinese)

Hegerl, G. C., and Coauthors, 2007: Understanding and Attributing Climate Change. Climate Change 2007: The Physical Science Basis. Contribution of Working Group I to the Fourth Assessment Report of the Intergovernmental Panel on Climate Change, Solomon et al., Eds., Cambridge University Press, Cambridge, United Kingdom and New York, NY, USA, 663-736.

Hoerling, M., J. Hurrell, J. Eischeid, and A. Phillips, 2006: Detection and attribution of twentieth-century northern and southern African rainfall change. J. Climate, 19, 3989-4008.

Huang, R., W. Chen, Y. Ding, and C. Li, 2003: Studies on the monsoon dynamics and interaction between monsoon and ENSO cycle. Chinese J. Atmos. Sci., 27, 484-501. (in Chinese)

Hunke, E., and J. Dukowicz, 1997: An elasticviscous-plastic model for sea ice dynamics. J. Phys. Oceanogr., 27, 1849-1867.

Hunke, E., and W. Lipscomb, 2004: The Los Alamos Sea Ice Model, documentation and software. Version 3.1. LA-CC-98-16. Los Alamos National Laboratory, Los
Alamos, NM, 56pp.

Hulme, M., 1996: Recent climatic change in the world's drylands. Geophys. Res. Lett., 23, 61-64.

Hulme, M., T. Osborn, and T. Johns, 1998: Precipitation sensitivity to global warming: Comparison of observations with HADCM2 simulations. Geophys. Res. Lett., 25, 3379-3382.

Johns, T., and Coauthors, 2004: HadGEM1-Model description and analysis of preliminary experiments for the IPCC Fourth Assessment Report. Met Office Hadley Centre Technical Note No. 55, Met Office Hadley Centre for Climate Prediction and Research/Met Office, Exeter, United Kingdom. [Available online from http://www.metoffice.gov.uk/research/hadleycentre /pubs/HCTN/index.html]

Johns, T., and Coauthors, 2006: The new Met Office Hadley Centre climate model HadGEM1: Evaluation of coupled simulations. J. Climate, 19, 1327-1353.

Kendall, M., 1955: Rank Correlation Methods. 2nd ed., Oxford University Press, New York, 196pp.

Kim, H.-J., B. Wang, and Q. Ding, 2008: The global monsoon variability simulated by CMIP3 coupled climate models. J. Climate, 21, 5271-5294.

Kripalani, R., A. Kulkarni, S. Sabade, and M. Khandekar, 2003: Indian monsoon variability in a global warming scenario. Natural Hazards, 29, 189-206.

Lau, K., M. Kim, and K. Kim, 2006: Asian summer monsoon anomalies induced by aerosol direct forcing: The role of the Tibetan plateau. Climate Dyn., 26, 855-864.

Li, H., A. Dai, T. Zhou, and J. Lu, 2008: Responses of East Asian summer monsoon to historical SST and atmospheric forcing during 1950-2000. Climate Dyn., doi: $10.1007 / \mathrm{s} 00382-008-0482-7$.

Lipscomb, W., 2001: Remapping the thickness distribution in sea ice models. J. Geophys. Res., 106, 13989 14000 .

Menon, S., J. Hansen, L. Nazarenko, and Y. Luo, 2002: Climate effects of black carbon aerosols in china and india. Science, 297, 2250-2253.

Oki, T., and Y. Sud, 1998: Design of Total Runoff Integrating Pathways (TRIP) - A global river channel network. Earth Interactions, 2, 1-37.

Qian, Y., L. Leung, S. Ghan, and F. Giorgi, 2003: Regional climate effects of aerosols over china: modeling and observation. Tellus, B55, 914-934.

Roberts, D., and A. Jones, 2004: Climate sensitivity to black carbon aerosol from fossil fuel combustion. J. Geophys. Res., 109(D16202), doi: 10.1029/2004JD00 4676.

Roberts, M., 2004: The ocean component of HadGEM1. GMR Report Annex IV. D.3, Met Office, Exeter, United Kingdom.

Stott, P., G. Jones, J. Lowe, P. Thorne, C. Durman, T. Johns, and J. Thelen, 2006: Transient Climate Simulations with the HadGEM1 Climate Model: Causes of Past Warming and Future Climate Change. J. Climate, 19, 2763-2782. 
Trenberth, K. E., and J. W. Hurrell, 1994: Decadal atmosphere-ocean variations in the Pacific. Climate Dyn., 9, 303-319.

Wang, B., and LinHo, 2002: Rainy season of the AsianPacific summer monsoon. J. Climate, 15, 386-398.

Wang, B., and Q. Ding, 2006: Changes in global monsoon precipitation over the past 56 years. Geophys. Res. Lett., 33(L06711), doi: 10.1029/2005GL025347.

Webb, M., C. Senior, S. Bony, and J. Morcrette, 2001: Combining ERBE and ISCCP data to assess clouds in the Met Office Hadley Centre, ECMWF and LMD atmospheric climate models. Climate Dyn., 17, 905922.

Willmott, C., and K. Matsuura, 2001: Terrestrial air temperature and precipitation: Monthly and annual time series (1950-1999). [Available online from http://climate.geog.udel.edu/ climate/html_pages/ README.ghcn_ts2.html]

Xie, P., and P. Arkin, 1996: Analyses of global monthly precipitation using gauge observations, satellite estimates and numerical model precipitations. J. Climate, 9, 840-858.

Yang, X., Y. Guo, G. Xu, and X. Ren, 2002: Comparison of global spatio-temporal structures between interannual and interdecadal climate variations. Journal of Nanjing University (Natural Sciences), 38, 308-317. (in Chinese)

Yu, R., B. Wang, and T. Zhou, 2004: Tropospheric cooling and summer monsoon weakening trend over East Asia. Geophys. Res. Lett., 31(L22212), doi: 10.1029/2004GL021270.

$\mathrm{Yu}$, R., and T. Zhou, 2007: Seasonality and threedimensional structure of the interdecadal change in
East Asian monsoon. J. Climate, 20, 5344-5355.

Zhao, P., and Z. Zhou, 2005: East Asian subtropical summer monsoon index and its relationships to rainfall. Acta Meteorologica Sinica, 63, 933-941. (in Chinese)

Zhou, T., and R. Yu, 2006: Twentieth-Century surface air temperature over China and the globe simulated by coupled climate models. J. Climate, 19, 5843-5858.

Zhou, T., L. Zhang, and H. Li, 2008a: Changes in global land monsoon area and total rainfall accumulation over the last half century. Geophys. Res. Lett., 35, L16707, doi: 10.1029/2008GL034881.

Zhou, T., R. Yu, H. Li, and B. Wang, 2008b: Ocean forcing to changes in global monsoon precipitation over the recent half century. J. Climate, 21(15), 38333852 .

Zhou, T., D. Gong, J. Li, and B. Li, 2009a: Detecting and understanding the multi-decadal variability of the East Asian Summer Monsoon-Recent progress and state of affairs. Meteorologische Zeitschrift, 18(4), 455-467.

Zhou, T., and Coauthors, 2009b: Why the western Pacific subtropical high has extended westward snice the late 1970s. J. Climate, 22, 2199-2215.

Zhou, T., and J. Zhang, 2009c: Harmonious inter-decadal changes of July-August upper tropospheric temperature across the North Atlantic, Eurasian continent and North Pacific. Adv. Atmos. Sci., 26, 656-665.

Zhou, T., and Coauthors, 2009d: The CLIVAR C20C Project: Which components of the Asian-Australian Monsoon circulation variations are forced and reproducible? Climate Dyn., 33, 1051-1068, doi: 10.1007/s00382-008-0501-8. 